\title{
Estimating the Prevalence and Frequency of the Adolescent Drug Use: Do the Models Fit the Measures?
}

John P. Hoffmann

Brigham Young University - Provo, john_hoffmann@byu.edu

Stephen J. Bahr

Brigham Young University - Provo

Follow this and additional works at: https://scholarsarchive.byu.edu/facpub

Part of the Family, Life Course, and Society Commons, Gender and Sexuality Commons, Medicine and Health Commons, and the Sociology of Religion Commons

\section{Original Publication Citation}

Hoffmann, John P., and Stephen J. Bahr. 2010. “Estimating the Prevalence and Frequency of Adolescent Drug Use: Do the Models Fit the Measures?" Journal of Drug Issues 40(4): 871-900.

\section{BYU ScholarsArchive Citation}

Hoffmann, John P. and Bahr, Stephen J., "Estimating the Prevalence and Frequency of the Adolescent Drug Use: Do the Models Fit the Measures?" (2010). Faculty Publications. 3904.

https://scholarsarchive.byu.edu/facpub/3904 


\title{
Estimating the Prevalence and Frequency of Adolescent Drug Use: Do the Models Fit the MEASURES? ${ }^{1}$
}

\begin{abstract}
John P. Hoffmann, Stephen J. Bahr
We critically review recent studies to examine the measurement schemes and empirical models used to examine adolescent drug use, with a particular eye toward determining whether differences between the prevalence and frequency of use have been addressed. Several theoretical models suggest that there are differences but we find relatively few studies that have considered prevalence versus frequency, even though selection effects that dictate these processes affect conclusions about predictors of drug use. Using data from the 2004 U.S. National Survey of Drug Use and Health (NSDUH), $(n=16,235)$, we provide an empirical example of why distinguishing prevalence and frequency of use is important. In particular, gender, age, and parent-child arguments are associated with the prevalence, but are not associated with the frequency of drug use. The associations between grades, religiousness, positive parental relations and drug use are overestimated substantially absent controls for the selection process inherent in the shift from any use to frequency of use. We therefore contend that adolescent drug use studies require greater attention to this selection process.
\end{abstract}

\section{INTRODUCTION}

An issue that continues to draw attention from scholars, policy experts, government officials, and concerned citizens across the globe is adolescent substance use. Although many adolescents who use illicit substances maintain a relatively

\footnotetext{
John P. Hoffmann is Professor of Sociology at Brigham Young University. His research interests include the etiology of adolescent drug use and juvenile delinquency, drug use over the life course, and the association between school experiences and adolescent behaviors. Stephen J. Bahr is Professor of Sociology at Brigham Young University. He received his B.S. and M.S. from Brigham Young University and his Ph.D. from Washington State University. He previously taught at the University of Texas at Austin and was a professional fellow at the Bush Institute for Child and Family Policy, University of North Carolina, Chapel Hill. His research interests include prisoner reentry, drug treatment, evaluation research, adolescent drug use, separation, divorce, and remarriage.
} 


\section{Hoffmann, Bahr}

healthy lifestyle, others find their lives affected significantly by drug use. For example, studies suggest that adolescent drug use is associated with later problems such as low educational achievement, disrupted workforce participation, health problems, and difficulties with family life (Bachman et al., 1997, 2008; Macleod et al., 2004). Hence, etiological and public health research on this issue remains vital (Santelli et al., 2003; Toumbourou et al., 2007).

Although the overall prevalence of several types of drug use has diminished over the last 20 years, there continues to be a significant proportion of the adolescent population that uses various illegal drugs. For example, a 2009 survey of U.S. high school seniors indicated that $43.5 \%$ drank alcohol in the month prior to the survey, $27.4 \%$ reported "getting drunk," and $23.3 \%$ had used an illicit drug (Johnston, O'Malley, Bachman, \& Schulenberg, 2009). The research community has responded with numerous research and treatment projects, including studies of the prevalence and trends in drug use and abuse, correlates of drug use, and treatment outcomes for those diagnosed as dependent or substance abusers. In fact, a review of the Social Science Citation Index (SSCI) from 2000 to 2010 revealed approximately 842 articles that included the terms adolescent, teen or youth, and drug use, drug abuse, substance use, or substance abuse in their titles. A common goal of this research is to understand why some youths begin to use drugs and why a subset begins to use regularly. Hence, a substantial body of research has focused on the etiology of adolescent drug use.

Before any study of drug use is undertaken, researchers must conceptualizeoften tacitly - what they mean by drug use and decide what it is specifically about drug use they wish to measure. For example, are they interested in any drug use or only certain forms of use (e.g., drugs illegal for adults only)? They must then decide how to measure drug use. Should a participation, frequency, or variety scale be used? Finally, they have to make decisions about the most appropriate way to analyze the data they have collected to answer their particular research questions. For instance, what type of regression model, if any, should be used? Such decisions are critical as results and conclusions depend on how drug use is conceived, measured, and analyzed.

The purpose of this paper is to explore some of the implications of measurement and analysis decisions and how they affect conclusions about what predicts adolescent drug use. We suggest that, although there has been extensive research on the predictors of adolescent drug use, there is inadequate attention given to some important measurement and analysis decisions. In particular, many studies fail to address the distinction between prevalence of use and frequency of use. Yet, it is clear that there is a selection process that occurs as youths move from any use to more frequent forms of use. Moreover, based on theoretical and empirical research 


\section{Prevalence and Frequency of Adolescent Drug Use}

that addresses adolescent behaviors, the predictors of prevalence and frequency are likely to differ. Without carefully attending to the differences between prevalence and frequency, researchers may reach the wrong conclusions about which factors affect each. Thus, after briefly reviewing how adolescent drug use has been measured and models of use analyzed, we address this specific issue. Using data from a national survey that was conducted in the U.S., we show that, after adjusting for the selection process that differentiates prevalence from frequency, the predictors of each aspect of drug use differ. We conclude with a discussion of why careful attention to measurement and analysis issues is vital to our understanding of adolescent drug use.

\section{Measuring Adolescent Drug Use}

A fundamental decision that researchers make involves how to measure adolescent drug use. For example, is one more interested in initiation, general prevalence, or frequency of use? Is some notion of intensity or problem use, such as dependence or abuse, particularly germane? There are obviously many ways one might measure drug use among young people; yet the reasons for adopting a particular measurement scheme are not always clearly articulated by researchers. When using secondary data, the reason may be practical: the researcher uses whatever scale is available. Nevertheless, how drug use is conceptualized, measured, and analyzed are interrelated, for the conceptual rationale has crucial implications for what measurement scheme is adopted, and the measurement scheme dictates what type of empirical model is chosen.

To demonstrate the variety of conceptual and measurement schemes in etiological research, we conducted a literature review of adolescent drug use studies published in peer reviewed journals from 2000-2010. ${ }^{2}$ We examined a total of 319 articles that included quantitative analyses, primarily in the form of predictive models, and discovered that there are eight general ways that have been used to measure adolescent drug use. Each of these measurement schemes reflects distinct ways to conceptualize what is meant by adolescent drug use:

1. Binary and trichomous measures of any use versus no use or any use, some use, and problematic use (e.g., Getz \& Bray, 2005; Hoffmann \& Cerbone, 2002).

2. Frequency measures where respondents report how often they have used a substance over a specified period of time, such as a month or a year (e.g., Reid, Peterson, Hughey, \& Garcia-Reid, 2006; Walls, 2008).

3. Amount of use, such as the average number of ounces of alcohol consumed per day or the average number of cigarettes smoked per day (e.g., Barr, Farrell, Barnes, \& Welte, 1993).

4. Amount by frequency, which gauges, for instance, cross-classifications of use with average amount consumed (e.g., Amoateng \& Bahr, 1986). Measures

FALL 2010

873 


\section{Hoffmann, Bahr}

of heavy drinking are also amount by frequency measures (e.g., Wechsler \& Wuethroch, 2002).

5. Duration of use examines how long some form of drug use lasts, from initiation to cessation (e.g., Dishion, Capaldi, \& Yoerger, 1999; Green \& Ritter, 2000).

6. Guttman scaling typically involves cumulative lifetime involvement in drug use, such as no use, use of only cigarettes and alcohol, marijuana use but no other illicit drugs, illicit drugs other than marijuana, and use of prescribed drugs in addition to other illicit drugs. The rationale for this approach is that drug use typically follows a sequential pattern among adolescents, with cigarette and alcohol use followed by marijuana use, then the use of other illicit drugs (Kandel, 1990; Kandel, 2002).

7. Summated scaling by summing or combining various drug use items. This may involve adding the number of drugs a respondent reports using, or summing frequency items for, say, alcohol, marijuana, cocaine, crack, and other drug use (e.g., oxycontin, heroin, LSD, and amphetamines) (e.g., Eleck, Miller- Day, \& Hecht, 2006; Hoffmann, 2002; Trinidad \& Johnson, 2002). The items may also be weighted based on the presumed severity of specific drugs (Brook, Whiteman, Brook, \& Gordon, 1991).

8. Latent variable/class scaling uses some type of confirmatory factor model to develop an underlying continuum of drug use (e.g., Bahr, Maughan, Marcos, \& Li, 1998; Hoffmann \& Su, 1998; Mason, Hitch, \& Spoth, 2009; Nash, McQueen, \& Bray, 2005; Reid et al., 2006). A presumed advantage of latent variable approaches is that they attenuate measurement error by isolating a "true" score of drug use based on common response patterns to various questions about drug use. ${ }^{3}$

Our review indicates that the most common type of measure is frequency of use (31\%) followed by a binary categorization into users and non-users $(21 \%)$. Next are summated scales $(14 \%)$, amount used (11\%), amount by frequency $(9 \%)$, and latent variable scales $(8 \%)$. However, as mentioned earlier, these measurement decisions are driven by objectives that are rarely articulated by researchers. For example, are researchers interested only in the prevalence of use or the frequency of use? Why is one objective chosen over others? It is clear that some of these choices are dictated by data availability, with many researchers limited to what is available in a secondary data set. Yet, even in this situation, it is important to identify how drug use is conceptualized, such as whether any involvement is favored over frequency of use. Moreover, it is important to understand these choices because how drug use is measured drives the choice of the empirical model, which ultimately affects conclusions about the predictors of adolescent drug use. ${ }^{4}$ 


\section{Prevalence and Frequency of Adolescent Drug Use}

\section{Analyzing Measures of Adolescent Drug Use}

The type of empirical analysis a researcher chooses is normally based on the statistical properties of the measurement or coding scheme. For example, when binary indicators are used, logistic or probit regression is the most common statistical model; whereas frequency and summated scales are typically analyzed with a linear regression model. In our review of previous studies, we identified four general types of empirical models, as well as a number of other types that we placed under a miscellaneous category. Table 1 provides a frequency distribution of these models. Almost two-fifths of the studies used logistic or probit regression. This is not surprising given the large number of studies that measure drug use using a binary or trichotomous scale. A variation of this approach is event history/survival analysis where the researchers predict time until first use of a drug (Wagner \& Anthony, 2002).

In $17 \%$ of the studies we reviewed, researchers used multiple linear regression as the principal analysis method. A growing number of studies $-12 \%$ but with a positive trend across the years-utilized structural equation modeling (SEM) to predict drug use. This type of analysis also tends to use a linear regression approach (but with maximum likelihood (ML) estimation), although the measurement of drug use is based on a confirmatory factor model that identifies a latent variable (e.g., Bahr et al., 1998; Mason et al., 2009). Many studies that use linear regression or SEMs attempt to normalize the distributions of drug use scales since these distributions tend to be heavily skewed. However, few of these studies question the assumption of continuity of these scales. Unlike frequency measures, a true continuous scale can take on any possible value within the limits of the scale's range. Thus, some researchers opt to consider frequency scales or latent variables as count variables and use Poisson or negative binomial regression to model them (e.g., Fergusson, Boden, $\&$ Horwood, 2006). Finally, there are a few studies that assume that drug use should be placed into latent classes, which are then assumed to follow a Poisson distribution or are analyzed using semi- or nonparametric techniques (e.g., Stormshak, Comeau, \& Shepard, 2004; Windle \& Wiesner, 2004).

\section{Distinguishing the Prevalence and Frequency of Drug Use}

As suggested by this review, there are diverse measurement schemes and analytic models utilized by researchers who study adolescent drug use. However, there is also an important, if not essential, issue that has often been neglected. That is, the distinction between any use (prevalence) and frequency of use is too rarely discussed or attended to in empirical studies (Wu, Korper, Marsden, Lewis, \& Bray, 2003). Yet there is clearly a difference between any use of a drug and frequent use of a drug or multiple drugs. After using a substance, many youths discontinue use, some continue to use occasionally, while others use regularly. The factors that predict each of these may differ. Take, for example, a youth who used marijuana on one occasion in the

FALL 2010 
Table 1. Frequency of Using Different Types of Analysis in Adolescent Drug Use Studies, 2000-2010

Type of Analysis

Correlations, tabulations ${ }^{1}$

Logistic/probit regression

Multiple linear regression

Structural equation modeling ${ }^{2}$

Other analytic techniques ${ }^{3}$

Note. The results are based on a literature review that was completed in April 2010. Some studies contributed more than one type of analysis since they may have included more than one empirical model.

'Studies where correlations and/or cross tabulations were the primary methods of analysis.

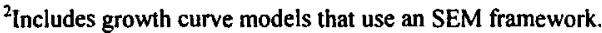

${ }^{3}$ Includes event history/survival models, latent class/transition analysis, IRT/Rasch modeling, canonical variate analysis, generalized estimating equations (GEEs), multilevel models (including growth curve models), log-linear models, analysis of variance/covariance techniques, and zero-inflated/tobit models.
Number of Studies

77 


\section{Prevalence and Frequency of Adolescent Drug Use}

Farrington, 1992; Paternoster \& Triplett, 1988; Ramoutar \& Farrington, 2006). Others have concluded that estimating models that do not distinguish between prevalence and frequency do not result in misleading conclusions. However, they have also noted that there have been few systematic analyses of this issue (Nagin \& Smith, 1990).

This remains an important issue not only in the delinquency literature, but also for research on adolescent drug use. Moreover, there are not only empirical reasons for distinguishing prevalence from frequency, but also important theoretical reasons. Consider, for example, the following notable theories of adolescent deviance.

First, social control theory is the basis for some commonly used predictors of drug use, such as bonds to parents, religious involvement, and grades in school. This theory posits that these bonds help constrain youths from taking or abusing drugs (Hirschi, 1969). Given the pervasiveness of alcohol and drug use in American society, most adolescents and adults are exposed to drugs and may be inclined to use if there are no social controls provided through families, peers, and religious organizations. Research has shown that bonds to families, schools, and religious organizations may be important in deterring drug use (Bachman et al., 2008; Bahr et al., 1998; Bahr \& Hoffmann, 2008). However, as suggested below, because of changes in the brain, strain, reward contingencies, and social networks, these bonds may become less salient for frequency of use than for prevalence of use.

Second, according to neurobiological theory, variables that influence prevalence may be different than the variables that influence the frequency of use. Characteristics such as family bonds and peers influence the initial choice to use a drug but may have less impact on frequency of use. Neurobiological theorists conceive of drug dependence as a chronic brain disorder; the extent and nature of the disease influences the frequency of use (Leschner, 1997). In recent years, neurobiological researchers have confirmed that drug use can change the structure of the brain which, in turn, influences future drug using behavior (Koob \& Simon, 2009; Powledge, 1999).

Third, strain theory considers drug use as a response to various types of stress. Agnew (2006) postulated that strains tend to result in negative emotional states such as anger, frustration, jealously, depression, and fear. These emotions lead to pressure for corrective action, reduce ability to cope in a legal manner, and decrease concern with the costs of drug use. Strains may not only influence decisions to use or not to use but may also alter the influence of social control variables (such as bonds to parents and religious involvement) on the frequency of use.

Fourth, much of the research on peers and drug use is based on social learning theory (Akers \& Sellers, 2004; Catalano et al., 1996; Petraitis, Flay, \& Miller, 1995). According to this perspective, an individual learns to use drugs in small, informal groups such as peer groups and families. It is in these intimate settings 


\section{Hoffmann, Bahr}

that individuals acquire attitudes regarding drugs and their use. The causal learning mechanisms are modeling, rewards, punishments, and direct teachings through networks of associates (Akers, 1998). As physical tolerance for a drug increases, a higher frequency of use may be necessary to receive the same effect, which may alter social networks and change reward structures so that constraints from family bonds and non-using friends may become less important.

Finally, labeling theorists distinguish between primary and secondary deviance (Becker, 1963; Lemert, 1951). The initial use of a drug may be considered primary deviance while frequency of use may be conceived as secondary deviance. Among users, how frequently they use may be influenced by informal and formal reactions to their use. This suggests that variables influencing frequency may be different than those that influence the choice to use a drug.

To summarize, according to several notable theoretical perspectives, predictors of prevalence are likely to be different than the predictors of frequency of use. This is the case for social control and neurobiological theory, but strain, social learning, and labeling theories may also be understood as providing reasons why predictors of prevalence may be different from predictors of frequency. However, additional theoretical and empirical work is needed to specify the extent to which predictors of the prevalence of use vary from predictors of frequency of use.

As we have shown, many studies have examined either the prevalence or the frequency of adolescent drug use. Few studies investigate both or hypothesize whether the same or different factors predict one or the other form of drug use. Yet, there are important theoretical and empirical reasons for distinguishing prevalence and frequency. To demonstrate why this issue is vital, we offer an illustration of this point by providing an analysis that exhibits the risks of ignoring the distinction between prevalence and frequency. Although the conceptual approach in the following analysis is based in social control theory, our general point also applies to research that relies on other theoretical models.

\section{An Analysis of Selection Effects in Models of Adolescent Drug Use}

Our review of adolescent drug use studies indicates that researchers often choose a regression model that fits the ostensible distribution of the outcome variable (e.g., OLS regression or SEM for continuous measures). However, as discussed earlier, there is little attention to explicitly recognizing the differences between prevalence and frequency or whether statistical models are used appropriately given these likely differences. Moreover, frequency scales or latent variables normally assume a continuous distribution, whereas others argue that it is more appropriate, in many situations, to conceptualize these as count variables. In order to demonstrate why these issues are important, we developed several drug use scales derived from similar items included in the 2004 National Survey on Drug Use and Health (NSDUH), 


\section{Prevalence and Frequency of Adolescent Drug Use}

a large federal survey conducted periodically by the Substance Abuse and Mental Health Services Agency (SAMHSA) of the U.S. Department of Health and Human Services (HHS). We then estimated statistical models that matched the measurement properties of these scales to investigate whether these choices dictate the conclusions that are drawn from these types of analyses.

The 2004 NSDUH sample includes more than 16,000 adolescent respondents, ages $12-17$, who answered questions about various types of drug use. They also provided information about some commonly used explanatory variables such as grades in school, religious involvement, and relations with parents. As discussed earlier, social control theory is the basis for the expectation that grades, religious involvement, and relations with parents influence drug use behavior, although we posit that they are more germane to prevalence than to frequency of use.

The key set of outcome variables includes questions about past-year alcohol, marijuana, and other illicit drug use. Other illicit drugs include cocaine, methamphetamine, stimulants, hallucinogens, analgesics, oxycontin, tranquilizers, sedatives, and inhalants. An interesting characteristic of the NSDUH is that it is one of the only national surveys in the U.S. that asks about the number of days in the pastyear adolescents used these various drugs, so a frequency score may be computed that ranges from zero to 365 . For example, the past-year marijuana question asks, "On how many days in the past 12 months did you use marijuana or hashish?" $\mathrm{Other}$ questions are phrased in a similar manner. This allows us to compute several drug use scales, including binary prevalence indicators, ordinal scales, and frequency and variety measures. Two of the frequency scales are based on the number of days in the past year adolescents reported using alcohol or marijuana. Another is based on past-month heavy drinking (five or more drinks per day), so it ranges from zero to 30 . An illicit drug frequency scale is based on the maximum number of days in the previous year adolescents reported using one of the drugs mentioned earlier. Hence, we have four frequency measures available for analysis.?

We also developed ordinal scales that capture frequency and variety of use and place different ranges into categories. These scales include two types. The first type collapses the frequency scales for marijuana, alcohol, binge drinking, and illicit drug use into seven categories: no use, used 1-2 days, used 3-5 days, used 6-9 days, used 10-19 days, used 20-39 days, or used 40 or more days in the previous year. Hence, it is similar to the past-year drug use items of Monitoring the Future (MTF, an annual high school and junior high school survey; Johnston et al., 2009), except that we assess days rather than "occasions." A second ordinal scale was developed for the illicit drug use items; it is based on a Rasch/IRT model (Bond \& Fox, 2001) derived from binary indicators of use of eight of the nine illicit drugs enumerated earlier. Rasch/IRT models are typically used to capture latent qualities of aptitude or 


\section{Hoffmann, Bahr}

ability on tests, but have also been used to construct latent drug use scales (Kirisci, Vanyukov, Dunn, \& Tarter, 2002). The specific model indicates the probabilities of using the various illicit drugs along a latent scale and increasing values indicate an increasing probability of answering yes to more items that asked about past-year substance use. The thresholds in the Rasch scale indicate at what point along the probability continuum a respondent is expected to increase in the number of drugs used from one number to the next.

The Rasch model that we estimated with the NSDUH data indicated that inhalant use did not load on the same latent scale as the other drugs, so it was omitted from the model. The results of the Rasch model were used to categorize users into seven categories of use from no use to use of seven or eight of the drugs in the previous year. Thus, unlike the previously described ordinal measure, the Rasch modeling approach results in a variety scale rather than a frequency scale (Bendixen, Endresen, \& Olweus, 2003).

The binary prevalence indicators are based on a simple dichotomy of non-use (coded 0 ) or use (coded 1) of alcohol, marijuana, or other drugs in the past year. The heavy drinking variable was collapsed into no heavy drinking versus heavy drinking in the past month. In sum, we use the following drug use measurement schemes: frequency (continuous) scales for four types of drug use, frequency (ordinal) scales for four types of drug use, a variety (ordinal) drug use scale based on the Rasch model, and binary prevalence scales for four types of drug use.

The regression models were chosen based on the presumed distribution of the drug use items. For example, we use a binary logistic regression model to analyze the binary indicators, an ordinal logistic regression model to analyze the ordinal drug use scales, and a negative binomial regression model to analyze the frequency of drug use scales (Hoffmann, 2004). For the binary logistic model, the logit (or log-odds) of drug use (yes vs. no) is modeled based on a set of explanatory variables. For the ordinal logistic, we rely on the proportional odds version of the regression model: we assume the log-odds of a response $\left(y_{i} \leq j\right.$ rather than $\left.y_{i}>j\right)$ are proportionally lower or higher across, say, two conditions where $x_{i}=x_{i}$ and $x_{i}=x_{2}$ (Powers \& Xie, 2000 ). In other words, we presuppose that the effects of an explanatory variable on the shift in the odds from one category to the next are invariant across categories. ${ }^{8}$ We utilize two types of negative binomial models to analyze the frequency scales:

- A model appropriate for counts, and

- A zero-inflated model that distinguishes non-users from users and simultaneously predicts counts for those who reported using.

The conceptual rationale is, first, that these frequency scales are best seen as count variables that are over-dispersed (the variance exceeds the mean; Hoffmann, 2004), thus linear regression or Poisson count models are normally not appropriate

Journal of Drug Issues 


\section{Prevalence and Frequency of Adolescent Drug Use}

(cf. Stormshak, Comeau, \& Shepard, 2004). Second, zero-inflated models are a type of censored regression model that assumes that distinct processes differentiate participation in a behavior (i.e., prevalence) such as drug use from frequency of a behavior (Connell, Dishion, \& Deater-Deckard, 2006; DeMaris, 2004). In particular, there is individual heterogeneity in drug use that needs to be considered. Failure to account for the selection process in a regression model can lead to biased slopes and standard errors (Cameron \& Trivedi, 1998), and may lead to erroneous conclusions concerning the predictors of the count process-or the positive values - of the outcome variable. A zero-inflated model differentiates these distinct processes, thus minimizing the bias that often affects other regression models that do not account for the selection process. Similar to a logistic regression, the zero-inflated portion of the model-labeled prevalence in the tables-distinguishes zeros (or no use) from positive use (the probability of being any positive value) in the model. An advantage of this model is that it also provides a frequency portion: it estimates the association between the explanatory variables and the frequency (count) of use among those who have a positive value of use (Cheung, 2002). ${ }^{9}$ Thus, the effects of the explanatory variables on both prevalence and frequency of use may be estimated with statistical adjustment for the selection process.

Some researchers have attempted to adjust for the selection process by utilizing a two-part regression model, with the first part a logistic model that distinguishes no use from any use and the second part a linear regression model that estimates frequency of use among those who report use. However, this leads to biased regression coefficients, especially in the second part of the model, since they are based on a nonrandom subsample of the data (Berk, 1983; Breen, 1996; DeMaris, 2004; Cameron \& Trivedi, 1998). It is likely that these biases will affect the conclusions about the predictors of the outcome; for example, we will likely misrepresent the statistical association between variables such as gender or grades and an outcome such as the frequency of marijuana use. Thus, a model that explicitly distinguishes the two-steps and adjusts for the selection process is preferred.

Given that the theories described earlier provide little direction about which variables are most influential at each stage of use, we used the same set of explanatory variables to model the prevalence and frequency of drug use. These include gender (coded $0=$ female and $1=$ male), age in years (range 12-17), and self-reported grades in school (a five point scale from very low to very high). Religiousness, which has been used to predict adolescent drug use in several studies (e.g., Bahr \& Hoffmann, 2008; Bahr et al., 1998; Sutherland \& Shepherd, 2001), is a latent variable determined through a confirmatory factor model that underlies religious service attendance, the notion that one's religious beliefs are very important in one's life, the notion that religious beliefs influence one's decisions, and a question about how important it is

FALL 2010 


\section{HoffMann, BaHR}

that one's friends share one's religious beliefs (eigenvalue $=1.997$; alpha $=0.77$ ). Parent-child relations, a common predictor of adolescent substance use drawn from social control theory (e.g., Hoffmann \& Su, 1998), are based on two questions: "During the past 12 months, how often did your parents let you know when you'd done a good job" and "During the past 12 months, how often did your parents tell you they were proud of you for something you had done?" The responses, which ranged from never (coded 0 ) to always (coded 3 ), were summed (gamma $=0.81$ ). Finally, one question was used to measure parent-child arguments: "During the past 12 months, how many times have you argued or had a fight with at least one of your parents." The response options were identical to those used to assess parent-child relations.

The control variables include race/ethnicity (based on a set of dummy variables to identify six different groups), family income, family structure (dummy variables that identify four groups), and residence in a metropolitan area (coded $0=$ no, $1=$ yes) (cf. Bachman et al., 2008; Hoffmann, 2002; Hollist \& McBroom, 2006). In each model, we adjusted the estimates for the complex sampling design of the NSDUH, as well as for non-response, and utilized probability weights to ensure that the estimates were nationally representative. Moreover, since we are examining if there are differences in the coefficients across models in order to determine whether there are distinct predictors of prevalence and frequency, we use a set of $z$-tests to determine whether coefficients are statistically distinct (Brame et al., 1998; Paternoster, Brame, Mazerolle, \& Piquero, 1998). ${ }^{10}$

\section{RESULTS}

The results of the analyses are shown in Tables 2-5. Table 2 includes the illicit drug use models. Note that the results of the binary logistic, ordinal logistic, Rasch models, and the prevalence portion of the zero-inflated models are quite similar. The direction and strength of effects do not differ much across these models. A set of $z$-tests indicate only minimal differences in the size of the coefficients. Although the coefficients are not directly comparable, the negative binomial model shows at least one distinct difference: The gender coefficient is not statistically significant. This suggests that females are more likely than males to use illicit drugs, but they do not tend to use more frequently than males, at least when frequency is viewed as the number of days of use. A set of $z$-tests indicates that the differences between this coefficient $(-0.052)$ and the gender coefficients from the other models $(-0.309$, $-0.237,-0.306$, and -0.232 ) are significantly distinct at $p<0.01$.

However, the frequency portion of the zero-inflated negative binomial regression model shows the most dramatic differences. Note that the coefficients are attenuated to a substantial degree in this model relative to the regular negative binomial model (the only coefficients that are not statistically significantly distinct-according to 
Table 2. Past-Year lllicit Drug Use by Adolescents Ages 12-17, U.S. National Survey on Drug Use and Health, 2004

\begin{tabular}{|c|c|c|c|c|c|c|}
\hline \multirow[b]{2}{*}{ Variable } & \multirow{2}{*}{$\begin{array}{l}\text { Binary } \\
\text { Logistic }\end{array}$} & \multirow{2}{*}{ Ordinal } & \multirow{2}{*}{$\begin{array}{c}\text { Ordinal } \\
\text { Logistic- } \\
\text { Rasch Model }\end{array}$} & \multirow{2}{*}{$\begin{array}{l}\text { Negative } \\
\text { Binomial }\end{array}$} & \multicolumn{2}{|c|}{$\begin{array}{c}\text { Zero-Inflated Negative } \\
\text { Binomial } \\
\end{array}$} \\
\hline & & & & & Prevalence & Frequency \\
\hline Gender & $\begin{array}{c}-0.309^{* * *} \\
(.058)\end{array}$ & $\begin{array}{l}-0.237^{* * *} \\
(.060)\end{array}$ & $\begin{array}{c}-0.306^{* * *} \\
(.059)\end{array}$ & $\begin{array}{c}-0.052 \\
(.110)\end{array}$ & $\begin{array}{c}-0.232^{*} \\
(.103)\end{array}$ & $\begin{array}{c}-0.045 \\
(.095)\end{array}$ \\
\hline Age & $\begin{array}{l}0.258^{* * *} \\
(.026)\end{array}$ & $\begin{array}{l}0.152^{* * *} \\
(.021)\end{array}$ & $\begin{array}{l}0.266^{* * *} \\
(.026)\end{array}$ & $\begin{array}{l}0.147^{* * *} \\
(.036)\end{array}$ & $\begin{array}{l}0.209^{* * *} \\
(.036)\end{array}$ & $\begin{array}{c}-0.002 \\
(.030)\end{array}$ \\
\hline Grades in school & $\begin{array}{l}-0.396^{* * *} \\
(.041)\end{array}$ & $\begin{array}{l}-0.369 * * * \\
(.034)\end{array}$ & $\begin{array}{c}-0.398 * * * \\
(.040)\end{array}$ & $\begin{array}{l}-0.515^{* * *} \\
(.065)\end{array}$ & $\begin{array}{l}-0.445^{* * *} \\
(.071)\end{array}$ & $\begin{array}{l}-0.164^{* * *} \\
(.048)\end{array}$ \\
\hline Religiousness & $\begin{array}{l}-0.425^{* * *} \\
(.043)\end{array}$ & $\begin{array}{l}-0.381 * * * \\
(.039)\end{array}$ & $\begin{array}{l}-0.448^{* * *} \\
(.043)\end{array}$ & $\begin{array}{l}-0.470^{* * *} \\
(.086)\end{array}$ & $\begin{array}{l}-0.479^{* * *} \\
(.070)\end{array}$ & $\begin{array}{r}-0.152^{*} \\
(.062)\end{array}$ \\
\hline $\begin{array}{l}\text { Relations with } \\
\text { parents }\end{array}$ & $\begin{array}{l}-0.441^{* * *} \\
(.051)\end{array}$ & $\begin{array}{l}-0.442^{* * *} \\
(.045)\end{array}$ & $\begin{array}{l}-0.454^{* * *} \\
(.050)\end{array}$ & $\begin{array}{l}-0.481^{* * *} \\
(.064)\end{array}$ & $\begin{array}{l}-0.570^{* * *} \\
(.014)\end{array}$ & $\begin{array}{l}-0.142^{* *} \\
(.053)\end{array}$ \\
\hline $\begin{array}{l}\text { Arguments with } \\
\text { parents }\end{array}$ & $\begin{array}{l}0.203^{* * *} \\
(.025)\end{array}$ & $\begin{array}{l}0.210^{* * *} \\
(.023)\end{array}$ & $\begin{array}{l}0.211^{* * *} \\
(.025)\end{array}$ & $\begin{array}{l}0.208^{* * *} \\
(.031)\end{array}$ & $\begin{array}{l}0.321^{* * *} \\
(.038)\end{array}$ & $\begin{array}{l}-0.018 \\
(.030)\end{array}$ \\
\hline $\begin{array}{l}\text { Overdispersion } \\
\text { parameter }\end{array}$ & & & & $\begin{array}{l}3.474^{* * * *} \\
(.033)\end{array}$ & & \\
\hline
\end{tabular}

Note. Standard errors appear in parentheses. Illicit drug use includes the number of days in the past year adolescents reported using cocaine. methamphetamine, stimulants, hallucinogens, analgesics, oxycontin, tranquilizers. sedatives, and inhalants. The binary logistic model estimates pastyear use as a binary indicator $(0=70,1=y e s)$. The ordinal logistic model estimates past-ycar use as no use, used $1-2$ days, used 3-5 days, used 6-9 days, used 10-19 days, used 20-39 days, or used 40 or more days. The Rasch model includes an ordinal scale from 0-7 based on binary indicators of each drug; inhalants are omitted from this scaie. The negative binomial model estimates the number of days respondents reported use in the past year. The zero-inflated negative binomial model distinguishes prevalence of use and frequency of use anong those who reported past-year use. The models control for the effects of race/ethnicity, family structure, family income. and residence in a metropolitan area. The estimates are based on weighted data and are adjusted for the multistage sampling design of the NSDUH. The sample size is 16,235 .

${ }^{*} p<, 05 ; * * p<.01: * * * p<001$

$z$-tests - are those for gender). For example, the coefficient for religiousness is attenuated by about $68 \%(-.479 \rightarrow-.152)$, whereas the "arguments with parents" coefficient is no longer statistically significant in the frequency part of the zeroinflated model. This strongly suggests that failing to consider the selection process that dictates a difference between prevalence and frequency of illicit drug use leads to questionable conclusions about the factors that predict this outcome.

The other models provide similar results. In each analysis (see Tables 3-5), there are important differences across the binary or ordinal models and the frequency models. For example, a positive gender effect emerges when assessing frequency of marijuana use or heavy drinking, but gender is not associated with frequency of alcohol use (z-tests indicate these differences are statistically significant). Moreover, in each model the coefficients (with the exception of gender in Tables 2 and 4) in the frequency portion of the zero-inflated models are attenuated to a statistically significant degree relative to those from the regular negative binomial model $(p<0.01)$. 


\section{Hoffmann, Bahr}

Given that distributions of drug use frequency variables usually have high proportions of zeros (those with no use; or those who do not participate in drug use), we contend that the results from the frequency part of the zero-inflated negative binomial regression models--which consider the selection process inherent in drug use scales-are more valid than those from logistic regression or a standard negative binomial model. Yet the most common analysis technique in recent studies has been logistic regression (see Table 1). If we had reported results using binary or ordinal logistic regression, or the standard negative binomial model, our conclusions regarding the predictors of drug use-especially the frequency of use - would have been misleading. Consider illicit drug use; for example: we would have generally concluded that gender, age, and arguments with parents all are significantly associated with illicit drug use in general (see Table 2). Furthermore, we would have reported that the effects of grades, religiousness, and relations with parents on frequency of use were much stronger than in fact they were. Actually, these factors may be consequential when considering the prevalence of drug use, but they are not as predictive when it comes to frequency of use. Moreover, given the similarities between the logistic, ordinal logistic, the standard negative binomial regression models, and the prevalence portion of the zero-inflated model, we suspect that the shift from no use to some use has the most substantial impact in these models. This seems likely given the plurality of respondents who reported no use in the past year or no heavy drinking in the past month. In each case, the shift from no use to any use is the most consequential part of the model. Importantly, frequency of use is not distinguished well in these models, nor is the selection process identified."

The lessons from this analysis are, first, that there are important differences between binary or ordinal depictions of adolescent drug use and frequency measures. Second, accounting for the process that distinguishes any use from the process that distinguishes frequency of use is vital. We risk overestimating the impact of several common predictors if we assume that the same process dictates both patterns of use; in other words, if we ignore the selection bias that is a part of these models. For example, it appears that the association between arguing with parents or having good relations with parents and marijuana, alcohol, or other illicit drugs is driven primarily by the tendency of those who argue more or do not get along with their parents to cross some threshold that dictates any use. But parent-child arguments and poor relations are rather unhelpful for understanding more frequent patterns of use. In a more general sense, this suggests that some frequently studied bonds between parents and adolescents are more germane to prevalence than to frequency of drug use. 
Table 3. Past-Year Marijuana Use by Adolescents Ages 12-17, U.S. National Survey on Drug Use and Health, 2004

\begin{tabular}{|c|c|c|c|c|c|}
\hline \multirow[b]{2}{*}{ Variable } & \multirow{2}{*}{$\begin{array}{l}\text { Binary } \\
\text { Logistic }\end{array}$} & \multirow{2}{*}{$\begin{array}{l}\text { Ordinal } \\
\text { Logistic }\end{array}$} & \multirow[b]{2}{*}{ Negative Binomial } & \multicolumn{2}{|c|}{$\begin{array}{c}\text { Zero-Inflated Negative } \\
\text { Binomial }\end{array}$} \\
\hline & & & & Prevalence & Frequency \\
\hline Gender & $\begin{array}{r}-0.016 \\
(.060)\end{array}$ & $\begin{array}{l}0.035 \\
(.063)\end{array}$ & $\begin{array}{l}0.437^{* * *} \\
(.130)\end{array}$ & $\begin{array}{c}-0.054 \\
(.079)\end{array}$ & $\begin{array}{l}0.344^{* * *} \\
(.070)\end{array}$ \\
\hline Age & $\begin{array}{l}0.528 * * * \\
(.024)\end{array}$ & $\begin{array}{l}0.525^{* * * *} \\
(.024)\end{array}$ & $\begin{array}{l}0.693^{* * *} \\
(.052)\end{array}$ & $\begin{array}{l}0.591^{* * *} \\
(.031)\end{array}$ & $\begin{array}{l}0.109 * * \\
(.033)\end{array}$ \\
\hline Grades in school & $\begin{array}{l}-0.497 * * * \\
(.038)\end{array}$ & $\begin{array}{l}-0.500^{* * *} \\
(.036)\end{array}$ & $\begin{array}{l}-0.806^{* * *} \\
(.078)\end{array}$ & $\begin{array}{l}-0.548^{* * *} \\
(.050)\end{array}$ & $\begin{array}{l}-0.197^{* * *} \\
(.031)\end{array}$ \\
\hline Religiousness & $\begin{array}{c}-0.476^{* * *} \\
(.046)\end{array}$ & $\begin{array}{c}-0.487^{* * *} \\
(.045)\end{array}$ & $\begin{array}{c}-1.000^{* * *} \\
(.097)\end{array}$ & $\begin{array}{c}-0.533^{* * *} \\
(.063)\end{array}$ & $\begin{array}{c}-0.264^{* * *} \\
(.050)\end{array}$ \\
\hline $\begin{array}{l}\text { Relations with } \\
\text { parents }\end{array}$ & $\begin{array}{l}-0.296 * * * \\
(.046)\end{array}$ & $\begin{array}{l}-0.323^{* * *} \\
(.046)\end{array}$ & $\begin{array}{l}-0.565^{* * *} \\
(.111)\end{array}$ & $\begin{array}{l}-0.322^{* * *} \\
(.064)\end{array}$ & $\begin{array}{l}-0.175^{* *} \\
(.050)\end{array}$ \\
\hline $\begin{array}{l}\text { Arguments with } \\
\text { parents }\end{array}$ & $\begin{array}{l}0.233^{* * *} \\
(.029)\end{array}$ & $\begin{array}{l}0.229 * * * \\
(.029)\end{array}$ & $\begin{array}{l}0.264^{* * *} \\
(.065)\end{array}$ & $\begin{array}{l}0.287^{* * *} \\
(.029)\end{array}$ & $\begin{array}{l}0.005 \\
(.029)\end{array}$ \\
\hline \multicolumn{2}{|c|}{$\begin{array}{l}\text { Overdispersion } \\
\text { parameter }\end{array}$} & & $\begin{array}{l}3.311^{* * *} \\
(.033) \\
\end{array}$ & \multicolumn{2}{|c|}{$\begin{array}{l}0.649 * * * \\
(.011) \\
\end{array}$} \\
\hline \multicolumn{6}{|c|}{$\begin{array}{l}\text { Note. Standard errors appear in parentheses. Marijuana use includes the number of days in the past year adolescents reported using } \\
\text { marijuana. The binary logistic model estimates past-year use as a binary indicator }(0=\text { no, } 1=\text {-yes). The ordinal logistic model estimates } \\
\text { past-year use as no use, used } 1-2 \text { days, used } 3-5 \text { days, used } 6-9 \text { days, used } 10-19 \text { days, used } 20-39 \text { days, or used } 40 \text { or more days. The } \\
\text { negative binomial model estimates the number of days respondents reported use in the past year. The zero-inflated negative binomial } \\
\text { model distinguishes prevalence of use and frequency of use among those who reported past-year use. The models control for the effects } \\
\text { of race/ethnicity, family structure, family income, and residence in a metropolitan area. The estimates are based on weighted data and } \\
\text { are adjusted for the multistage sampling design of the NSDUH. The sample size is } 16,235 \text {. }\end{array}$} \\
\hline
\end{tabular}

FALL 2010 
Table 4. Past-Year Alcohol Use by Adolescents Ages 12-17, U.S. National Survey on Drug Use and Health, 2004

\begin{tabular}{|c|c|c|c|c|c|}
\hline \multirow[b]{2}{*}{ Variable } & \multirow{2}{*}{$\begin{array}{c}\text { Binary } \\
\text { Logistic }\end{array}$} & \multirow{2}{*}{$\begin{array}{l}\text { Ordinal } \\
\text { Logistic }\end{array}$} & \multirow{2}{*}{$\begin{array}{l}\text { Negative } \\
\text { Binomial }\end{array}$} & \multicolumn{2}{|c|}{$\begin{array}{c}\text { Zero-Inflated Negative } \\
\text { Binomial }\end{array}$} \\
\hline & & & & Prevalence & Frequency \\
\hline Gender & $\begin{array}{l}-0.175^{* *} \\
(.052)\end{array}$ & $\begin{array}{c}-0.107^{*} \\
(.046)\end{array}$ & $\begin{array}{l}0.035 \\
(.101)\end{array}$ & $\begin{array}{l}0.144 \\
(.076)\end{array}$ & $\begin{array}{l}0.050 \\
(.063)\end{array}$ \\
\hline Age & $\begin{array}{l}0.527^{* * *} \\
(.018)\end{array}$ & $\begin{array}{l}0.516^{* * *} \\
(.017)\end{array}$ & $\begin{array}{l}0.560^{* * *} \\
(.025)\end{array}$ & $\begin{array}{l}0.681^{* * *} \\
(.031)\end{array}$ & $\begin{array}{l}0.160^{* * *} \\
(.019)\end{array}$ \\
\hline Grades in school & $\begin{array}{c}-0.302^{* * *} \\
(.027)\end{array}$ & $\begin{array}{l}-0.314^{* * *} \\
(.023)\end{array}$ & $\begin{array}{l}-0.483^{* * *} \\
(.049)\end{array}$ & $\begin{array}{l}-0.324^{* * *} \\
(.048)\end{array}$ & $\begin{array}{l}-0.222^{* * *} \\
(.032)\end{array}$ \\
\hline Religiousness & $\begin{array}{c}-0.479 * * * \\
(.036)\end{array}$ & $\begin{array}{l}-0.412 * * * \\
(.033)\end{array}$ & $\begin{array}{l}-0.451^{* * *} \\
(.069)\end{array}$ & $\begin{array}{l}-0.659 * * * \\
(.047)\end{array}$ & $\begin{array}{r}-0.082^{*} \\
(.039)\end{array}$ \\
\hline $\begin{array}{l}\text { Relations with } \\
\text { parents }\end{array}$ & $\begin{array}{l}-0.291^{* * *} \\
(.039)\end{array}$ & $\begin{array}{l}-0.296 * * * \\
(.035)\end{array}$ & $\begin{array}{l}-0.317^{* * *} \\
(.074)\end{array}$ & $\begin{array}{l}-0.371^{* * * *} \\
(.060)\end{array}$ & $\begin{array}{l}-0.171^{* * * *} \\
(.042)\end{array}$ \\
\hline $\begin{array}{l}\text { Arguments with } \\
\text { parents }\end{array}$ & $\begin{array}{l}0.267^{* * *} \\
(.019)\end{array}$ & $\begin{array}{l}0.242^{* * *} \\
(.017)\end{array}$ & $\begin{array}{l}0.256^{* * *} \\
(.040)\end{array}$ & $\begin{array}{l}0.415^{* * *} \\
(.030)\end{array}$ & $\begin{array}{l}0.035 \\
(.021)\end{array}$ \\
\hline \multicolumn{2}{|l|}{$\begin{array}{l}\text { Overdispersion } \\
\text { parameter }\end{array}$} & & $\begin{array}{l}2.197^{* * *} \\
(.022)\end{array}$ & \multicolumn{2}{|c|}{$\begin{array}{l}0.529 * * * \\
(.010)\end{array}$} \\
\hline \multicolumn{6}{|c|}{$\begin{array}{l}\text { Note. Standard errors appear in parentheses. Alcohol use includes the number of days in the past year adolescents reported using } \\
\text { alcohol. The binary logistic model estimates past-year use as a binary indicator }(0=\text { no, } 1=\text { yes). The ordinal logistic model estimates } \\
\text { past-year use as no use, used 1-2 days, used } 3-5 \text { days, used } 6-9 \text { days, used } 10-19 \text { days, used } 20-39 \text { days, or used } 40 \text { or more days. The } \\
\text { negative binomial model estimates the number of days respondents reported use in the past year. The zero-inflated negative binomial } \\
\text { model distinguishes prevalence of use and frequency of use among those who reported past-year use. The models control for the effects } \\
\text { of race/ethnicity, family structure, family income, and residence in a metropolitan area. The estimates are based on weighted data and } \\
\text { are adjusted for the multistage sampling design of the NSDUH. The sample size is } 16,235 \text {. }\end{array}$} \\
\hline
\end{tabular}

${ }^{*} p<.05 ;{ }^{* *} p<.01 ; * * * p<.001$ 


\section{Table 5. Past-Month Binge Drinking by Adolescents Ages 12-17, U.S. National Survey on Drug Use and Health, 2004}

\begin{tabular}{|c|c|c|c|c|c|}
\hline \multirow[b]{2}{*}{ Variable } & \multirow[b]{2}{*}{ Binary Logistic } & \multirow{2}{*}{$\begin{array}{l}\text { Ordinal } \\
\text { Logistic }\end{array}$} & \multirow{2}{*}{$\begin{array}{l}\text { Negative } \\
\text { Binomial }\end{array}$} & \multicolumn{2}{|c|}{$\begin{array}{c}\text { Zero-Inflated Negative } \\
\text { Binomia! }\end{array}$} \\
\hline & & & & Prevalence & Frequency \\
\hline Gender & $\begin{array}{l}0.065 \\
(.086)\end{array}$ & $\begin{array}{l}0.088 \\
(.089)\end{array}$ & $\begin{array}{l}0.236^{*} \\
(.109)\end{array}$ & $\begin{array}{c}-0.150 \\
(.133)\end{array}$ & $\begin{array}{l}0.192^{* *} \\
(.065)\end{array}$ \\
\hline Age & $\begin{array}{l}0.569^{* * * *} \\
(.028)\end{array}$ & $\begin{array}{l}0.576^{* * * *} \\
(.028)\end{array}$ & $\begin{array}{l}0.612 * * * \\
(.034)\end{array}$ & $\begin{array}{c}0.733^{* * * *} \\
(.084)\end{array}$ & $\begin{array}{c}0.075^{*} \\
(.034)\end{array}$ \\
\hline Grades in school & $\begin{array}{c}-0.326^{* * *} \\
(.038)\end{array}$ & $\begin{array}{c}-0.328^{* * *} \\
(.038)\end{array}$ & $\begin{array}{c}-0.368^{* * *} \\
(.066)\end{array}$ & $\begin{array}{c}-0.451^{* * * *} \\
(.094)\end{array}$ & $\begin{array}{r}-0.055 \\
(.040)\end{array}$ \\
\hline Religiousness & $\begin{array}{c}-0.452^{* * * *} \\
(.051)\end{array}$ & $\begin{array}{c}-0.455^{* * *} \\
(.052)\end{array}$ & $\begin{array}{c}-0.487^{* * *} \\
(.069)\end{array}$ & $\begin{array}{c}-0.672^{* * *} \\
(.135)\end{array}$ & $\begin{array}{r}-0.067 \\
(.038)\end{array}$ \\
\hline $\begin{array}{l}\text { Relations with } \\
\text { parents }\end{array}$ & $\begin{array}{c}-0.297^{* * *} \\
(.052)\end{array}$ & $\begin{array}{c}-0.308^{* * *} \\
(.053)\end{array}$ & $\begin{array}{c}-0.466^{* * * *} \\
(.110)\end{array}$ & $\begin{array}{c}-0.305^{* *} \\
(.098)\end{array}$ & $\begin{array}{c}-0.167^{* *} \\
(.048)\end{array}$ \\
\hline $\begin{array}{l}\text { Arguments with } \\
\text { parents }\end{array}$ & $\begin{array}{l}0.178^{* * *} \\
(.024)\end{array}$ & $\begin{array}{l}0.188 * * * \\
(.024)\end{array}$ & $\begin{array}{l}0.202^{* * *} \\
(.043)\end{array}$ & $\begin{array}{l}0.181^{* * *} \\
(.053)\end{array}$ & $\begin{array}{l}0.058^{*} \\
(.028)\end{array}$ \\
\hline $\begin{array}{l}\text { Overdispersion } \\
\text { parameter }\end{array}$ & & & $\begin{array}{l}2.202^{* * *} \\
(.050) \\
\end{array}$ & \multicolumn{2}{|c|}{$\begin{array}{l}0.748^{* * *} \\
(.124)\end{array}$} \\
\hline \multicolumn{6}{|c|}{$\begin{array}{l}\text { Note. Standard ertors appear in parentheses. Binge drinking includes the number of days in the past month adolescents reported } \\
\text { having five or more drinks of alcohol on one occasion. The binary logistic model estimates past-month binge drinking as a } \\
\text { binary indicator ( } 0=\text { no. } 1=y \text { es). The ordinal logistic model estimates past-month binge drinking as no use, used } 1-2 \text { days. used } \\
3-5 \text { days, used } 6-9 \text { days, used } 10-19 \text { days, used } 20-39 \text { days, or used } 40 \text { or more days. The negative binomial model estimates } \\
\text { the number of days respondents reported binge drinking in the past month. The zero-inflated negative binomial model } \\
\text { distinguishes prevalence of use and frequency of use among those who reported past-year use. The models control for the } \\
\text { effects of race/ethnicity, family structure, family income, and residence in a metropolitan area. The estimates are based on } \\
\text { weighted data and are adjusted for the multistage sampling design of the NSDUH. The sample size is } 16.235 \text {. }\end{array}$} \\
\hline
\end{tabular}

FALL 2010 


\section{Hoffmann, Bahr}

\section{Conclusions}

This paper serves two general purposes. First, it is designed to draw attention to the need to provide a clearer picture of measurement and analysis decisions in studies of the etiology of adolescent drug use. Second, it focuses on the implications of selection processes when examining adolescent drug use-in particular, the likely differences between models of the prevalence and models of the frequency of use. Rather than simply relying on previous studies to dictate the measurement of drug use, we encourage the research community to take a more careful approach and think through measurement and analysis decisions. For example, there is clearly a distinction between participation in any use and more frequent use that should be considered before adopting a binary or an ordinal indicator. This is shown plainly when we analyze data from the NSDUH. Although the binary and ordinal models show similar results, the frequency models that account for the selection process reveal some important distinctions. The zero-inflated negative binomial model demonstrates, for instance, that we risk overestimating the association between predictors of any use and more frequent use. It is clear that there are important distinctions between prevalence and frequency of use that should be considered in models designed to predict adolescent drug use. Zero-infiated or censored regression models that are designed to identify lower bounds and distinguish between zero use and positive use should thus be considered as particularly appropriate for quantitative studies of adolescent drug use frequency (e.g., Duarte, Escario, \& Molina, 2005; Liu \& Powers, 2005; Windle \& Wiesner, 2004).

Note that this argument applies to other measures of drug use as well. For example, latent variable models are designed to measure an unobservable scale of drug use based on observable indicators. However, we found few examples of latent variable models that distinguished the use/no use dichotomy from frequency of use (e.g., Connell, Dishion, \& Deater-Deckard, 2006). If a latent variable analysis treats its no-users in the same way statistically as it treats its frequent users, then biases are highly likely. A latent class approach may offer a more suitable analytic tool since most studies include a class of no use. A study by Reboussin \& Anthony (2001), for example, examined the association between parental supervision and separate classes of adolescent drug use using a generalized logistic model. Similar to our results, they found that higher parental supervision-another ostensible measure of parent-child bonding — predicted no use vs. any use; it did not predict differences between classes of more frequent use. Thus, if ordinal scales and classes are preferred, we recommend a generalized or multinomial logistic approach rather than the proportional odds model that is commonly used. A multinomial model allows explicit comparisons among each category or class of drug use, thus obviating the need to assume that the explanatory variables predict shifts across categories 


\section{Prevalence and Frequency of Adolescent Drug Use}

in a consistent manner (Cameron \& Trivedi, 1998). An alternative approach is to use a mixture model or an ordinal random effects regression model (RMM) to estimate classes or trajectories of use and then consider whether covariates predict membership in or change to a particular group (e.g., Hedeker \& Mermelstein, 2000; Windle \& Wiesner, 2004). Whichever model is adopted, researchers should attempt to consistently differentiate and account for the differences between participation in and frequency of adolescent drug use.

Another important issue is distinguishing problematic forms of use from any use. In an analysis not shown, we estimated a multinomial logistic regression model predicting three outcomes - no use, use but no dependence, and drug dependence - based on variables constructed for the NSDUH. There is not sufficient space to elaborate the results fully, but we found that the explanatory variables did a much better job distinguishing use-non-dependence from no use than distinguishing dependence from the other two outcomes. Hence, models designed to predict drug dependence or abuse should be carefully constructed to consider all possible categories of use.

In addition, there is a significant need to develop richer theoretical models of adolescent drug use that explain not only the decision to participate in various forms of use, but also that explain why some youth become more frequent users. Moreover, why do some youths cross the threshold from use to problematic or abusive forms of use? Earlier we briefly discussed how social control, neurobiological, strain, social learning, and labeling theories may provide reasons why predictors of any use are different from predictors of frequency of use or abuse. However, as noted above, conceptualizing the differences between prevalence and frequency using these models of adolescent deviance is underdeveloped and additional theoretical and empirical work is needed to specify the extent to which predictors of frequency or abuse differ from predictors of prevalence or initiation. There are also other promising conceptual models that may prove useful as we seek to develop more thorough explanations of prevalence and frequency (Clark, 2010).

Of course, there are many additional methodological and empirical issues that are not addressed in this analysis. We consider only one particular selection issue, which concerns the process that determines, of those who use drugs, who uses more frequently. However, there are other types of selection issues to consider. Perhaps the most well-known involves the use of sampling techniques that fail to identify a random sample of the population or that do not sample hard-to-reach populations (e.g., homeless or runaway youths). Under coverage of certain groups is clearly a serious problem for studies of drug use. Moreover, this study does not address potential biases due to non-response, social desirability, or faulty recall. Finally, there are issues that remain problematic when using cross-sectional data,

FALL 2010

889 


\section{Hoffmann, BaHR}

especially establishing the temporal order of explanatory and outcome variables (Wu et al., 2003). This paper speaks only to the types of empirical models that are most appropriate when faced with the selection process that dictates prevalence and frequency of adolescent drug use.

Finally, it is clear that adolescent drug use research is a multidisciplinary, yet often fragmented, endeavor, attracting scholars from criminology, medicine, psychology, social work, public health, anthropology, family science, economics, and sociology. So it is unsurprising that studies often emphasize one measurement or modeling strategy while ignoring or underemphasizing others. This applies not only to disciplinary emphases on prevalence versus frequency measures, but also to whether attention is focused on selection biases, particular predictors of use (e.g., physiological vs. social-psychological), and the use of conceptual models that describe the causal structure of initiation, continuation, or cessation. Perhaps what is needed most is genuine cross-disciplinary collaboration that will lead to a more comprehensive understanding of adolescent drug use. Moreover, selection effects should be considered in all studies that examine the frequency of this behavior.

\section{Notes}

1. A earlier version of this paper was presented at the annual meeting of the American Society of Criminology, Los Angeles, CA, November 2006. Work on this paper was funded partly by grants DA12679 and DA11293 from the National Institute on Drug Abuse (NIDA). We would like to thank Jennifer Mendoza, Lish Harris, Ben McKune, and Rachael Lizon for research assistance. We also thank the anonymous reviewers for helpful comments and suggestions.

2. We limited the review to journals from medicine, public health, economics, psychology, and sociology but also included journals that specifically addressed drug and alcohol use (e.g., Journal of Drug Issues, Substance Use \& Misuse, Journal of Studies on Alcohol and Drugs) or adolescents (e.g., Journal of Adolescent Research). The review focused on articles designed to predict adolescent drug use; thus, we did not include studies of drug treatment or prevention, unless the article included a model that predicted drug use in some way (e.g., a prevention study that included a follow-up of those exposed to prevention efforts).

3. A related approach involves using latent class analysis or mixture modeling to identify categories of drug use. This may reflect the actual nature of drug use, which arguably is better represented by classes than by a continuous latent variable. For example, researchers have used latent class analysis to develop three, four, or five classes of adolescent drug use that include no use to frequent use (Chung, Flaherty, \& Schafer, 2006; Reboussin \& Anthony, 2001). Others have estimated mixture models or ordinal random effects models to develop 
class-based trajectories of use, such as low/rare use and early accelerating use (e.g., Connell, Dishion, \& Deater-Deckard, 2006; Hedeker \& Mermelstein 2000). Similarly, a latent variable may be developed using item response theory (IRT)/ Rasch modeling. In this approach, the score of drug use is conceptualized as the count of the thresholds on a latent trait. The thresholds are assumed to exist on a continuous scale, but respondents are placed within a particular ordered category based on their response patterns. Although the observed scales are frequently binary indicators of different types of drug use, these models may be extended to frequency variables through multilevel modeling techniques (Cheong \& Raudenbush, 2000; Kirisci et al., 2002).

4. We are certainly not accusing researchers of intellectual laziness or ignorance in their tacit choices about measurement strategies and empirical models. Rather, we only wish to encourage researchers to give more thought to these choices - and articulate this thought process - when presenting the results of their studies. For, as we intend to demonstrate, these choices have important implications for the results of and conclusions that stem from empirical models of adolescent drug use.

5. Even sophisticated methodological reviews and suggestions for modeling substance use measures often fail to address selection issues (e.g., Neal \& Simons, 2007), and, when they do, it is usually in terms of missing values or respondents who drop out of longitudinal studies (e.g., Rose, Chassin, Presson, Hughey, \& Garcia-Reid, 2000). Nevertheless, a common area of adolescent drug use research that may be most closely related to the issue of prevalence versus frequency involves the stages of drug use. As articulated in detail by Kandel (e.g., Kandel, 2002; Kandel, Kessler, \& Margulies, 1978; Kandel, Treman, Faust, \& Single, 1977), distinct factors tend to predict the stage of drug use among adolescents, with, for example, peer drug use most important for the likelihood of marijuana use and parent-child relations more important for the likelihood of progression to other illegal drugs. Yet, as Yamaguchi (2002, p. 283) pointed out when commenting about research on the stages of drug use, "In the analysis of non-experimental data, one needs to control for the selection bias of individuals into the use of a lower-stage drug when predicting progression to the next stage . . control [variables] do not completely eliminate the possibility of spuriousness. In the future, all approaches need to improve the handling of selection bias ... "We suggest that this observation applies to all studies of drug use frequency.

6. Respondents were also given the choice of answering the past-year questions by averaging the number of days per week or per month that they used the particular substance. We do not explore the implications of these different measurement strategies in this analysis. See also note 7. 


\section{Hoffmann, Bahr}

7. Although it is likely that these frequency measures are affected by recall bias, we do not pursue the issue of measurement error in this study. To compensate for presumed recall bias, some researchers arbitrarily set a ceiling on the number of days a respondent may have used, whereas others simply categorize frequency of use into a set of ordinal outcomes. We use ordinal scales to replicate this latter decision.

8. We examined the proportional odds assumption (Hoffmann, 2004) and found it is mainly violated in the shift from no use to some use. We suggest the reason for this violation in a later discussion.

9. We also considered several other censored regression models that are appropriate for non-normally distributed variables. These included censored least absolute deviations (CLAD), symmetrically censored least squares (SCLS), identically censored least absolute deviations (ICLAD), and a mixed effects, mixed distribution (MEMD) model (Chay \& Powell, 2001; Tooze, Grunwald, \& Jones, 2002). Unfortunately, these models failed to converge to a reasonable solution. We suspect this is because of the large sample size of the NSDUH, although more research is needed to fully examine this problem.

10. The results of the full set of $z$-tests are available from the authors upon request.

11. In each case, the zero-inflated negative binomial model fit the data better than the standard negative binomial model, according to the Bayesian Information Criterion (BIC) and the Akaike Information Criterion (AIC). Moreover, the variables presented in Tables 2-5 were generally statistically significant and had relatively large slopes in the zero-inflated portion of the model, whereas they had smaller slopes and larger standard errors in the frequency portion of the models. This lends further credence to our position that the largest influence of the variables is on the transition from no use to some use, rather than on the frequency of use.

\section{References}

Akers, R.L.

1998 Social learning and social structure: A general theory of crime and deviance. Boston: Northeastern University Press.

Akers, R.L. \& Sellers, C.S.

2004 Criminological theories: Introduction, evaluation, and application. Los Angeles: Roxbury Publishing Company.

Agnew, R.

2006 Pressured into crime: An overview of general strain theory. Los Angeles: Roxbury Publishing Company. 


\section{Prevalence ano Frequency of Adolescent Drug Use}

Amoateng, A., \& Bahr, S.J.

1986. Religion, family, and adolescent drug use. Sociological Perspectives, 29, $53-76$.

Bachman, J.G., O’Malley, P.M., Schulenberg, J.E., Johnson, L.D., FreedmanDoan, P., \& Messersmith, E.D.

2008 The education-drug use connection: How successes and failures in school relate to adolescent smoking, drinking, drug use, and delinquency. New York: Lawrence Erlbaum Associates.

Bachman, J.G., Wadsworth, K.N., O’Malley, P.M., Johnston, L.D., \& Schulenberg, J.E.

1997 Smoking, drinking, and drug use in young adulthood. Mahwah, NJ: Lawrence Erlbaum Associates.

Bahr, S.J., \& Hoffmann, J.P.

2008 Religiosity, peers, and adolescent drug use. Journal of Drug Issues, 38, 743-770.

Bahr, S.J., Maughan, S.L., Marcos, A.C., \& Li, B.

1998 Family, religiosity, and the risk of adolescent drug use. Journal of Marriage and the Family, 60, 979-992.

Barr, K.E.M., Farrell, M.P., Barnes, G.M., \& Welte, J.W.

1993 Race, class, and gender differences in substance abuse: Evidence of middle-class/underclass polarization among black males. Social Problems, 40, 314-327.

Becker, H.S.

1963 Outsiders: Studies in the sociology of deviance. New York: Free Press.

Bendixen, M., Endresen, I.M., \& Olweus, D.

2003 Variety and frequency scales of antisocial involvement: Which one is better? Legal and Criminological Psychology, 8, 135-150.

Berk, R. A.

1983 An introduction to sample selection bias in sociological data. American Sociological Review, 48, 386-398.

Boardman, J.D., Finch, B.K., Ellison, C.G., Williams, D.R., \& Jackson, J.S.

2001 Neighborhood disadvantage, stress, and drug use among adults. Journal of Health and Social Behavior, 42, 151-165.

Bond, T.G., \& Fox, C.M.

2001 Applying the Rasch model. Mahwah, NJ: Lawrence Erlbaum Associates.

Brame, R., Paternoster, R., Mazerolle, P., \& Piquero, A.

1998 Testing for the equality of maximum-likelihood regression coefficients between two independent equations. Journal of Quantitative Criminology, 14, 245-261. 


\section{Hoffmann, BaHR}

Breen, R.

1996 Regression models censored, sample selected or truncated data. Thousand Oaks, CA: Sage Publications.

Brook, J.S., Whiteman, M., Brook, D.W., \& Gordon, A.S.

1991 Sibling influences on adolescent drug use: Older brothers on younger brothers. Journal of American Academy of Adolescent Psychiatry, 30, 958-966.

Cameron, A.C., \& Trivedi. P.K.

1998 Regression analysis of count models. New York: Cambridge University Press.

Catalano, R.F., Kosterman, R., Hawkins, J.D., Newcomb, M.D., \& Abbott, R.D.

1996 Modeling the etiology of adolescent substance use: A test of the social development model. Journal of Drug Issues, 26, 429-455.

Chay, K.Y., \& Powell, J.L.

2001 Semiparametric censored regression models. Journal of Economic Perspectives, 15, 29-42.

Cheong, Y.F., \& Raudenbush, S.W.

2000 Measurement and structural models for children's problem behaviors. Psychological Methods, 5, 477-495.

Cheung, Y.B.

2002 Zero-inflated models for regression analysis of count data: A study of growth and development. Statistics in Medicine, 21, 1461-1469.

Chung, H., Flaherty, B.P., \& Schafer, J.L.

2006 Latent class logistic regression: Application to marijuana use and attitudes among high school seniors. Journal of the Royal Statistical Society, Part $A, 169,723-743$.

Clark, T.T.

2010 Reviewing the connection between paradigms and theories to understand adolescent drug use. Journal of Child \& Adolescent Substance Abuse, 19, 16-32.

Connell, A.M., Dishion, T.J., \& Deater-Deckard, K.

2006 Variable- and person-centered approaches to the analysis of early adolescent substance use. Merrill-Palmer Quarterly, 52, 421-448.

DeMaris, A.

2004 Regression with social data: Modeling continuous and limited response variables. New York: John Wiley \& Sons.

Dishion, T.J., Capaldi, D.M., \& Yoerger, K.

1999 Middle childhood antecedents to progressions of male adolescent substance use. Journal of Adolescent Research, 14, 175-205. 


\section{Prevalence and Frequency of Adolescent Drug Use}

Duarte, R., Escario, J.J., \& Molina, J.A.

2005 Participation and consumption of illegal drugs among adolescents. International Advances in Economic Research, 11, 399-415.

Elek, E., Miller-Day, M., \& Hecht, M.L.

2006 Influences of personal, injunctive, and descriptive norms on early adolescent substance use. Journal of Drug Issues, 36, 147-172.

Fergusson, D.M., Boden, J.M., \& Horwood, L.J.

2006 Cannabis use and other illicit drug use: Testing the cannabis gateway hypothesis. Addiction, 101, 556-569.

Getz, J.G., \& Bray, J.H.

2005 Predicting heavy alcohol use among adolescents. American Journal of Orthopsychiatry, 75, 102-116.

Green, B.E., \& Ritter, C.

2000 Marijuana use and depression. Journal of Health and Social Behavior, 41, $40-49$.

Hedeker, D., \& Mermelstein, R.J.

2000 Analysis of longitudinal substance use outcomes using ordinal random effects regression models. Addiction, 95(Supplement), S381-394.

Hirschi, T.

1969 Causes of delinquency. Berkeley, CA: University of California Press. Hoffmann, J.P.

2002 The community context of family structure and adolescent drug use. Journal of Marriage and Family, 64, 314-330.

Hoffmann, J.P.

2004 Generalized linear models: An applied approach. Boston: Pearson. Hoffmann, J.P.

2006 Extracurricular activities, athletic participation, and adolescent alcohol use: Gender-differentiated and school-contextual effects. Journal of Health and Social Behavior, 47, 175-190.

Hoffmann, J.P., \& Cerbone, F.G.

2002 Parental substance use disorder and the risk of adolescent drug abuse: An event history analysis. Drug and Alcohol Dependence, 66, 255-264.

Hoffmann, J.P., \& Su, S.S.

1998 Parental substance use disorder, mediating variables, and adolescent drug use: A nonrecursive model. Addiction, 93, 1353-1366.

Hollist, D.R., \& McBroom, W.H.

2006 Family structure, family tension, and self-reported marijuana use: A research finding of risky behavior among youths. Journal of Drug Issues, 36, 975-998. 


\section{Hoffmann, Bahr}

Johnston, L.D., O’Malley, P.M., Bachman, J.G., \& Schulenberg, J.E.

2009 Teen marijuana use tilts up, while some drugs decline in use. University of Michigan News Service: Ann Arbor, MI. Retrieved on May 1, 2010 from http://www.monitoringthefuture.org.

Kandel, D.B.

1990 Parenting styles, drug use, and children's adjustment in families of young adults. Journal of Marriage and the Family, 52, 183-196.

Kandel, D.B. (Ed.)

2002 Stages and pathways of drug involvement: Examining the gateway hypothesis. New York: Cambridge University Press.

Kandel, D.B., Kessler, R.C., \& Margulies, R.Z.

1978 Antecedents of adolescent initiation into stages of drug use: A developmental analysis. Journal of Youth and Adolescence, 7, 13-40.

Kandel, D.B., Treiman, D., Faust, R., \& Single, E.

1977 Adolescent involvement in legal and illegal drug use: A multiple classification analysis. Social Forces, 55, 438-458.

Kirisci, L., Vanyukov, M., Dunn, M., \& Tarter, R.

2002 Item response theory modeling of substance use: An index based on 10 drug categories. Psychology of Addictive Behaviors, 16, 290-298.

Koob, G.F. \& Simon, E.

2009 The neurobiology of addiction: Where we have been and where we are going. Journal of Drug Issues, 39, 115-132.

Lemert, E.M.

1951 Social pathology. New York: McGraw Hill.

Leshner, A.I.

1997 Addiction is a brain disease, and it matters. Science, 278 (Oct), 45-47.

Liu, H., \&, Powers, D.A.

2005 Growth curve models for zero-inflated count data: An empirical application to smoking behavior. PRC Working Paper 04-05-08. Austin, TX: Population Research Center, University of Texas at Austin.

Macleod, J., Oakes, R., Copello, A., Crome, I., Egger, M., Hickman, M., Oppenkowski, T., Stokes-Lampard, H., \& Smith, G.D.

2004 Psychological and social sequelae of cannabis and other illicit drug use by young people. The Lancet, 363, 1579-1588.

Mason, W.A., Hitch, J.E., \& Spoth, R.L.

2009 Longitudinal relations among negative affect, substance use, and peer deviance during the transition from middle to late adolescence. Substance Use \& Misuse, 44, 1142-1159. 


\section{Prevalence and Frequency of Adolescent Drug Use}

Nagin, D.S., \& Farrington, D.P.

1992 The onset and persistence of offending. Criminology, 30, 501-523.

Nagin, D.S., \& Smith, D.A.

1990 Participation in and frequency of delinquent behavior: A test of structural differences. Journal of Quantitative Criminology, 6, 335-356.

Nash, S.G., McQueen, A., \& Bray, J.H.

2005 Pathways to adolescent alcohol use: Family environment, peer influence, and parental expectations. Journal of Adolescent Health, 37, 19-28.

Neal, D.J., \& Simons, J.S.

2007 Inference in regression models of heavily skewed alcohol use data: A comparison of ordinary least squares, generalized linear models, and bootstrap resampling. Psychology of Addictive Behaviors, 21, 441-452.

Paternoster, R., Brame, R., Mazerolle, P., \& Piquero, A.

1998 Using the correct statistical test for the equality of regression coefficients. Criminology, 36, 859-866.

Paternoster, R., \& Triplett, R.

1988 Disagregating self-reported delinquency and its implications for theory. Criminology, 26, 591-625.

Petraitis, J., Flay, B.R., \& Miller, T.Q.

1995 Reviewing theories of adolescent substance use: Organizing pieces in the puzzle. Psychological Bulletin, 117, 67-86.

Powers, D.A., \& Xie, Y.

2000 Statistical methods for categorical data analysis. San Diego, CA: Academic Press.

Powledge, T.M.

1999 Addiction and the brain. Bioscience, 49, 513-519.

Ramoutar, K.M., \& Farrington, D.P.

2006 Are the same factors related to participation and frequency of offending by male and female prisoners? Psychology, Crime \& Law, 12, 557-572.

Reboussin, B.A., \& Anthony, J.C.

2001 Latent class marginal regression models for modeling youthful drug involvement and its suspected influences. Statistics in Medicine, 20, 623-639.

Reid, R.J., Peterson, N.A., Hughey, J., \& Garcia-Reid, P.

2006 School climate and adolescent drug use: Mediating effects of violence victimization in the urban high school context. The Journal of Primary Prevention, 27, 281-293. 


\section{Hoffmann, Bahr}

Rose, J.S., Chassin, L., Presson, C.C., \& Sherman, S.J. (Eds.).

2000 Multivariate applications in substance use research: New methods for new questions. Mahwah, NJ: Lawrence Erlbaum Associates.

Santelli, J.S., Rogers, A.S., Rosenfeld, W.D., DuRant, R.H., Dubler, N., Morreale, M., English, A., Lyss, S., Wimberly, Y., \& Schissel, A.

2003 Guidelines for adolescent health research: A position paper from the society for adolescent medicine. Journal of Adolescent Health, 33, 396-409.

Stormshak, E.A., Comeau, C.A., \& Shepard, S.A.

2004 The relative contribution of sibling deviance and peer deviance in the prediction of substance use across middle childhood. Journal of Abnormal Child Psychology, 32, 635-649.

Sutherland, I., \& Shepherd, J.P.

2001 Social dimensions of adolescent substance use. Addiction, 96, 445-458. Tooze, J.A., Grunwald, G.K., \& Jones, R.H.

2002 Analysis of repeated measures data with clumping at zero. Statistical Methods in Medical Research, 11, 341-355.

Toumbourou, J.W., Stockwell, T., Neighbors, C., Marlatt, G.A., Sturge, J., \& Rehm, J.

2007 Interventions to reduce harm associated with adolescent substance use. The Lancet, 369, 1391-1401.

Trinidad, D.R., \& Johnson, C.A.

2002 The association between emotional intelligence and early adolescent tobacco and alcohol use. Personality and Individual Differences, 32, 95-105.

Wagner, F.A., \& Anthony, J.C.

2002 Into the world of illegal drug use: Exposure opportunity and other mechanisms linking the use of alcohol, tobacco, marijuana, and cocaine. American Journal of Epidemiology, 155, 918-925.

Walls, M.L.

2008 Marijuana and alcohol use in early adolescence: Gender differences among American Indian/First Nations youth. Journal of Drug Issues, 38, 1139-1160.

Wechsler, H., \& Wuethrich, B.

2002 Dying to drink: Confronting binge drinking on college campuses. New York: Rodale Books.

Windle, M., \& Wiesner, M.

2004 Trajectories of marijuana use from adolescence to young adulthood. Development and Psychopathology, 16, 1007-1027. 
Prevalence and Frequency of Adolescent Drug Use

Wu, L.T., Korper, S.P., Marsden, M.E., Lewis, C., \& Bray, R.M.

2003 Use of incidence and prevalence in the substance use literature: $A$ review. Rockville, MD: Substance Abuse and Mental Health Services Administration, Office of Applied Studies.

Yamaguchi, K.

2002 Stages of drug use progression: A comparison of methods, concepts, and operationalizations. In D.B. Kandel (Ed.), Stages and pathways of drug involvement: Examining the gateway hypothesis (pp. 270-286). New York: Cambridge University Press. 